\title{
Tensões nos discursos de professores e as ações da prática pedagógica em modelagem matemática
}

\author{
Andreia Maria Pereira de Oliveira* \\ Jonei Cerqueira Barbosa**
}

\begin{abstract}
Resumo
Neste artigo, apresentamos um estudo que analisou as ações requeridas na implementação da modelagem matemática na prática pedagógica que produzem tensões nos discursos de professores. Para tratar o propósito do estudo, utilizamos a categoria teórica tensões nos discursos inspirada em conceitos da teoria dos códigos de Basil Bernstein. Os dados referentes à pesquisa qualitativa foram coletados por meio de observações, entrevistas e documentos. Os resultados apontam as seguintes ações da prática pedagógica em modelagem matemática quando tensões foram manifestadas nos discursos dos professores: planejar o sequenciamento da aula; engajar os estudantes; discutir e intervir diante das respostas dos estudantes e decidir como abordar o conteúdo matemático. Palavras-chave: Modelagem matemática; Tensões nos discursos; Professores; Práticas pedagógicas.
\end{abstract}

\section{Tensions in teachers' discourses and the actions of the pedagogic practice in mathematical modelling}

\section{Abstract}

In this paper, we report a study that analyzed the actions required to implement mathematical modeling in pedagogical practice that produce tensions in teachers' discourses. For the purpose of the study, we used the theoretical category tensions in discourses inspired by concepts of the theory of codes by Basil Bernstein. The data relating to qualitative research were collected through observations, interviews and documents. The results suggest the following actions of pedagogic practice in mathematical modeling when tensions were manifested in the teachers' discourses: to plan the sequencing of the lesson; to engage students, to discuss and act on the responses of students and to decide how to approach the mathematical content.

Keywords: Mathematical modeling; Tensions in discourses; Teachers; Pedagogic practices.

\section{Considerações Iniciais}

A abordagem de situações e problemas provenientes de outras áreas do conhecimento, como, por exemplo, Biologia, Física, Química, do dia a dia ou de áreas profissionais tem sido utilizada nas aulas da disciplina Matemática como uma possibilidade para estudantes compreenderem como a matemática é usada na tomada de decisões na sociedade (SKOVSMOSE, 2007). O tratamento dessas situações e problemas por meio da matemática é caracterizado, na Educação Matemática, como modelagem matemática (BLUM et al., 2007; BARBOSA; CALDEIRA; ARAÚJO, 2007; BASSANEZI, 2002).

Por modelagem matemática ${ }^{1}$, designamos como um ambiente de aprendizagem no qual estudantes são convidados a indagar e/ou a investigar, usado a matemática, problemas movidos de outras áreas do conhecimento, de áreas profissionais ou do dia a dia (BARBOSA, 2009). A noção de ambiente de aprendizagem, discutida por Skovsmose (2000), diz respeito às condições oferecidas aos estudantes para a realização de atividades escolares.

Apesar dos argumentos para a inserção da modelagem nas práticas pedagógicas ${ }^{2}$, a presença deste ambiente de aprendizagem tem sido pontual nas aulas (NISS, BLUM; GALBRAITH, 2007). Um dos modos de uso de situações com referência à realidade por professores nas aulas tem sido discutido por Gainsburg (2008). O autor aponta que professores tem escolhido utilizar problemas e exemplos para mostrar como a matemática é aplicada para resolver problemas. Esse modo de utilização tem requerido por parte dos estudantes pouca ação para investigar os problemas, não tendo oportunidades para discutir o papel da matemática na tomada de decisões na sociedade. Além dessa possibilidade, professores têm usado essas situações para abordar o conteúdo matemático e para mostrar a importância e a utilidade da matemática no mundo e na vida dos estudantes.

Apesar dos diferentes modos de uso dessas situações, professores têm apresentado resistências, apontado as seguintes justificativas: insegurança em relação à utilização do conteúdo matemático para resolver os problemas (ALMEIDA; DIAS 2004);

* Endereço eletrônico: ampodeinha@ gmail.com

** Endereço eletrônico: jonei.cerqueira@ ufba.br 
falta de clareza sobre a organização e a condução das atividades em sala de aula; os programas préestabelecidos (BARBOSA, 2004); a organização da escola e suas rotinas estabelecidas e a relação com os demais pares (BARBOSA, 2002). Além disso, estudos empíricos mostram evidências de que professores têm manifestado inseguranças, dilemas, incertezas e tensões nos discursos para organizar e conduzir a modelagem nas práticas pedagógicas (OLIVEIRA; BARBOSA, 2011; OLIVEIRA, 2010; BLOMHØJ; KJELDSEN, 2006; BARBOSA, 2002).

Essas inseguranças, dilemas, incertezas e tensões identificadas nos discursos dos professores na implementação da modelagem nas práticas pedagógicas pelas pesquisas, apontam evidências de ações específicas realizadas pelos professores em sala de aula por conta da decisão do que fazer e como fazer para operacionalizá-la no contexto escolar.

Assim, neste artigo, analisaremos as ações requeridas pelos professores na implementação da modelagem matemática na prática pedagógica que produzem tensões nos discursos. A palavra discurso refere-se a um texto, produzido oralmente ou por escrito, pelo indivíduo que pertence a um determinado contexto social. De acordo com Bernstein (1990, p. 17), o texto é "a forma da relação social feita visível, palpável, material". Com isso, o texto tem o propósito materializar a comunicação entre sujeitos.

$\mathrm{O}$ artigo está organizado em seis seções. $\mathrm{Na}$ segunda seção, trazemos conceitos da teoria dos códigos de Bernstein (2000) para discutir a prática pedagógica dos professores quando professores movem modelagem para as aulas e a noção teórica tensões nos discursos. $\mathrm{Na}$ terceira seção, descrevemos o contexto e a metodologia do estudo. $\mathrm{Na}$ quarta e quinta seções, apresentamos e discutimos as ações da prática pedagógica requeridas no desenvolvimento do ambiente de modelagem quando professores manifestaram tensões nos discursos. Por fim, na última seção, trazemos as considerações finais do artigo.

\section{Modelagem matemática, professores e as tensões nos discursos}

A prática pedagógica em modelagem tem sido documentada nos estudos empíricos (OLIVEIRA; BARBOSA, 2011; OLIVEIRA, 2010; CHAPMAN, 2007; DOERR; ENGLISH, 2006; BLOMHØJ; KJELDSEN, 2006; LEI $\beta$, 2005), os quais têm focalizado: as intervenções dos professores no acompanhamento dos estudantes na resolução do problema (LEI $\beta, 2005)$; os conhecimentos pedagógicos mobilizados pelos professores na operacionalização da modelagem no contexto escolar (DOERR; ENGLISH, 2006); os dilemas dos professores na realização de trabalhos de projetos em modelagem (BLOMHØJ; KJELDSEN, 2006); as estratégias dos professores no desenvolvimento do ambiente de modelagem em sala de aula (CHAPMAN, 2007); as situações de tensão $^{3}$ na implementação de modelagem nas práticas pedagógicas (OLIVEIRA; BARBOSA, 2011)

Os resultados desses estudos apontam ações requeridas na prática pedagógica em modelagem para professores operacionalizarem esse ambiente de aprendizagem. Essas ações podem ser entendidas como princípios para posicionar um novo discurso, no caso, o discurso sobre modelagem na prática pedagógica. $\mathrm{O}$ processo de mover um discurso de uma posição para outra é definido por Bernstein $(1990,2000)$ como recontextualização pedagógica. $\mathrm{O}$ autor afirma que "quando um discurso é movido, por recontextualização, do seu contexto original para o contexto pedagógico, o discurso original é abstraído da sua base social, posição e relações de poder" (BERNSTEIN, 2000, p. 38). Assim, podemos citar as disciplinas escolares como exemplo de discursos recontextualizados, pois elas foram levadas do campo acadêmico e reposicionadas para servir a determinados propósitos no contexto escolar. Outro exemplo são os discursos sobre mudanças de práticas (como exemplo, modelagem, resolução de problemas, investigações matemáticas, etc.) que professores têm contato, por exemplo, nos espaços de formação e os movem para as práticas pedagógicas.

O movimento desses discursos para as práticas pedagógicas são controlados em relação ao que mover e como movê-los. Esse controle é operado pelo discurso pedagógico como designado por Bernstein (2000). De acordo com o autor, o discurso pedagógico é um princípio que seleciona discursos e os recoloca em relação a outros discursos já estabelecidos e presentes na prática pedagógica.

Bernstein (2000) apresenta três campos para explicar a construção e a reprodução do discurso pedagógico: o campo de produção, o campo de recontextualização e o campo de reprodução. $\mathrm{O}$ primeiro consiste do campo encarregado da construção de novos discursos, por exemplo, o discurso sobre matemática acadêmica que até ser 
transformado em um discurso sobre matemática escolar é apropriado do campo de produção e transformado em discurso pedagógico, sendo o campo de recontextualização responsável em fazer isso. Esse campo, quando composto pelo Estado e seus agentes, é chamado de campo de recontextualização oficial, e quando composto por formadores de professores, escritores de livros didáticos e periódicos especializados, etc., no caso do campo de recontextualização pedagógica. $\mathrm{O}$ terceiro campo é onde ocorre a prática pedagógica nas escolas. Portanto, a matemática escolar é um discurso pedagógico construído por recontextualização pedagógica do discurso especializado da matemática.

Em relação ao discurso sobre modelagem, quando ele é movido pelo professor (agente de recontextualização) para a prática pedagógica, o discurso pedagógico opera em termos da seleção e da organização do que e como mover esse discurso em termos dos discursos já presentes e consolidados na prática pedagógica. Em vista disso, o discurso pedagógico, por meio das regras presentes, consolidadas e construídas socialmente no contexto escolar, controla o modo como um discurso pode ser posicionado na prática pedagógica.

Assim, a relação dos professores com a modelagem pode ser entendida em termos de como eles transformam esse discurso, pois como agentes de recontextualização eles são responsáveis por selecionar o que e como mover o discurso sobre modelagem para as salas de aula em termos do que já realizam nas práticas pedagógicas. Bernstein (2000) utiliza dois termos para caracterizar os princípios de comunicação na prática pedagógica. Esses termos referem-se ao que falar e como falar, sendo nomeados, respectivamente, por classificação e enquadramento ${ }^{4}$. O primeiro refere-se ao conteúdo da comunicação na categoria, ou seja, $o$ que pode ser dito. $\mathrm{O}$ segundo refere-se às formas de comunicação legítima na prática pedagógica, as quais permitem determinar como algo pode ser dito.

Em um ambiente de modelagem, por exemplo, o professor pode não ter muita clareza sobre a seleção do conteúdo matemático requerido para resolver os problemas (ALMEIDA; DIAS 2004), sobre a organização, sequência, ritmo das atividades em sala de aula em relação aos programas pré-estabelecidos (BARBOSA, 2004) e sobre as estratégias que estudantes utilizam para resolver os problemas (DOERR; ENGLISH, 2006). Esses resultados podem trazer indícios das formas de comunicação legítima na prática pedagógica em modelagem relacionada ao conceito de enquadramento. Além disso, podemos pensar na relação do discurso sobre modelagem com os discursos presentes e consolidados na prática pedagógica relacionada ao conceito de classificação.

A relação do discurso sobre modelagem com os discursos presentes na prática pedagógica pode gerar descontinuidades entre esses discursos, constituindo inseguranças, dilemas, incertezas e tensões nos discursos (OLIVEIRA; BARBOSA, 2011; OLIVEIRA, 2010). Como consequência, os princípios comunicativos, o que pode ser dito e como algo pode ser dito, são alterados em sala de aula.

A categoria teórica tensões nos discursos foi utilizada em Oliveira e Barbosa (2011) e Oliveira (2010) para compreender as ações dos professores quando movem o discurso sobre modelagem para as práticas pedagógicas. Essas tensões nos discursos são manifestadas pelas contradições, rupturas e dilemas nos discursos constituídos por conta do espaço - o qual Bernstein (2000) denomina isolamento - que separa os discursos já constituídos social e historicamente na prática pedagógica, e outro discurso vindo de fora, no caso, o discurso sobre modelagem, quando ele é posicionado pelo professor, apresentando, assim, uma descontinuidade entre eles.

Portanto, as tensões nos discursos são resultado da descontinuidade entre discursos (discursos presentes na prática pedagógica e novos discursos), sendo identificadas nos discursos dos professores quando eles decidem o que pode ser dito e como pode ser dito nas práticas pedagógicas as quais eles participam. Essas tensões nos discursos agendam ações específicas que são produzidas por conta da decisão do que pode ser falado e como pode ser falado na presença de um novo discurso na prática pedagógica.

\section{$O$ contexto e a metodologia}

Os dados utilizados foram coletados nas aulas de três professores, denominados Boli, Maria e Vitória, pseudônimos escolhidos por eles. Esses professores implementaram modelagem pela primeira vez em turmas do ensino fundamental. Eles lecionavam em escolas públicas e particulares (no caso do professor Boli) em cidades do interior da Bahia, tendo mais de 14 anos de experiência na docência.

Boli escolheu o tema cesta básica para implementar uma atividade de modelagem em duas 
turmas do $9^{\circ}$ ano do ensino fundamental. Ele esquematizou os seguintes momentos para realizar atividade: apresentação do tema e do problema; discussão do significado de uma cesta básica; elaboração de uma cesta básica com os estudantes; organização da turma em grupos; entrega de um formulário para os grupos fazerem a pesquisa de preços dos produtos da cesta básica nos mercados; discussão dos preços das cestas elaboradas e comparação com a cesta básica proposta pelo governo. Maria escolheu o tema análise do consumo de água para implementar uma atividade de modelagem em uma turma do $7^{\circ}$ ano do ensino fundamental. Nesta atividade, os estudantes foram convidados pela professora para analisar as contas de água da casa deles e da escola.

Vitória escolheu o tema o salário mínimo $e$ o custo de vida de uma família em Conceição do Jacuípe para implementar uma atividade de modelagem em uma turma de Fluxo de Regularização Escolar ${ }^{5}\left(8^{\circ}\right.$ e $9^{\circ}$ anos do ensino fundamental). Ela esquematizou os seguintes momentos para realizar atividade: apresentação do tema; organização da turma em grupos; coleta das informações pelos estudantes; resolução do problema e sistematização.

Esses professores tiveram contato com modelagem no curso de Licenciatura em Matemática, no Programa de Formação de Professores de $6^{\circ}$ a $9^{\circ}$ anos do Ensino Fundamental e do Ensino Médio - Modalidade Presencial, em uma universidade pública, ao cursarem as disciplinas Metodologia e Estágio Supervisionado II e III. Esse programa foi proposto aos professores da rede pública que já lecionavam, mas não possuíam formação específica na área de atuação. Durante as disciplinas, eles tiveram a experiência com modelagem como estudante e como professor (BARBOSA, 2004). Eles tiveram a oportunidade de escolher um tema não matemático, formular problemas e investigá-lo por meio da matemática (a experiência como estudante) e elaborar, planejar e fazer uma atividade de modelagem nas práticas pedagógicas (a experiência como professor).

$\mathrm{O}$ estudo enquadra-se em uma abordagem qualitativa de pesquisa (DENZIN; LINCOLN, 2005), pois o propósito é analisar as ações requeridas na implementação da modelagem matemática na prática pedagógica quando professores manifestaram tensões nos discursos. Assim, a intenção é entender as ações da prática pedagógica em modelagem matemática que provocaram tensões nos discursos pelos professores, de modo que possamos elaborar constructos teóricos para compreender a dinâmica da realização de mudanças de práticas quando professores decidem mover discursos para a prática pedagógica.

A coleta de dados nas aulas de Matemática dos professores ocorreu quando eles fizeram modelagem pela primeira vez, a qual foi realizada, utilizando uma filmadora para o registro das aulas de cada professor, as observações. Após cada aula, foram realizadas entrevistas semiestruturadas, nas quais os professores comentaram como foi a implementação da modelagem nas práticas pedagógicas. Além das transcrições das filmagens e das entrevistas, utilizamos como materiais empíricos as narrativas escritas pelos professores sobre cada aula.

Após as transcrições dos dados, realizamos uma análise fundamentada na perspectiva de Bernstein (2000), o qual aponta a articulação entre dados e teoria para descrever o fenômeno estudado de maneira que forme uma relação dinâmica para geração de constructos teóricos na área de estudo. Essa relação dialética entre dados e teoria é caracterizada pelo autor como linguagem de descrição, a qual é formada pela linguagem interna e a linguagem externa. A linguagem de descrição interna refere-se aos conceitos contidos em uma teoria (no nosso caso, a teoria dos códigos de Bernstein) com o propósito de criar uma linguagem conceitual (modelo teórico) e a linguagem de descrição externa refere-se aos modelos provenientes da relação entre dados empíricos e a linguagem interna de descrição. A linguagem de descrição interna é ativada pela externa, possibilitando descrever algo mais do que a si própria (BERNSTEIN, 2000).

A partir desta noção teórica, utilizamos alguns conceitos da teoria dos códigos (linguagem descrição interna) para identificar e analisar as ações requeridas pela prática pedagógica quando professores manifestaram tensões nos discursos (linguagem descrição externa). Assim, a análise dos dados ocorreu em três fases: a primeira envolveu a leitura dos materiais empíricos de cada professor e a identificação de trechos que se relacionavam ao objetivo do estudo. Na segunda fase, ocorreu a leitura, linha por linha, dos trechos e a codificação deles. Esses códigos representaram as tensões nos discursos de cada professor. Em seguida, os códigos das tensões nos discursos foram comparados $\mathrm{e}$ agrupados nas dimensões das ações requeridas da prática pedagógica em modelagem matemática. $\mathrm{Na}$ terceira fase, essas dimensões das ações da prática 
pedagógica em modelagem matemática foram analisadas à luz da literatura e da teoria de Basil Bernstein.

\section{As ações requeridas na prática pedagógica em modelagem e as tensões nos discursos}

Nesta seção, inicialmente, apresentamos as tensões nos discursos manifestadas pelos professores na implementação do ambiente de modelagem em sala de aula. Assim, foram identificadas as seguintes tensões nos discursos: $a$ tensão do sequenciamento e do ritmo na prática pedagógica, a tensão da participação dos estudantes, a tensão da abordagem das respostas dos estudantes e a tensão da abordagem do conteúdo matemático. Essas tensões nos discursos foram manifestadas quando eles tiveram que decidir o que falar e como falar na recontextualização do discurso sobre modelagem nas práticas pedagógicas.

A seguir, trazemos cada tensão e as ações requeridas da prática pedagógica em modelagem, ilustrando com trechos dos dados.

\section{A tensão do sequenciamento e do ritmo na prática pedagógica}

Os professores desenvolveram o ambiente de modelagem em duas das quatro aulas semanais da disciplina Matemática, pois, em paralelo, eles cumpriram os conteúdos estabelecidos na programação curricular. Assim, eles planejaram o que dizer e como dizer, elaborando e sequenciando as atividades que estudantes desenvolveriam nas aulas.

Essa tensão foi identificada no discurso do professor Boli quando ele indagou: "Pergunto agora os itens da cesta básica ou coloco os itens no quadro? Formo os grupos agora? Será que eu faço isso agora ou não?" (OBSERVAÇÃO, Professor Boli) Assim, ele ficou preocupado em controlar a comunicação no ambiente de modelagem, já que a dinâmica das aulas (o envolvimento dos estudantes) desafiou o planejamento prévio das atividades.

Nesta tensão, podemos observar a maneira como o professor estabeleceu uma sequência e um ritmo para realizar as atividades planejadas nesse ambiente de modelagem. O ritmo refere-se à variação de tempo destinado a cada atividade da sequência planejada. Essa tensão aconteceu no momento em que o envolvimento dos estudantes na discussão do tema da atividade alterou o controle estabelecido pelo professor.

Nesta situação, dois discursos estiveram presentes, constituindo a tensão nos discursos denominada tensão do sequenciamento e do ritmo na prática pedagógica. $\mathrm{O}$ primeiro discurso referese a seguir a sequência das atividades planejadas na prática pedagógica, tendo relação com a dinâmica realizada por Boli nas aulas. Entretanto, o ambiente de modelagem alterou a dinâmica das aulas, uma vez que as atividades planejadas foram desenvolvidas em uma sequência e ritmo não apenas controlados por Boli, mas também pelos estudantes. $\mathrm{O}$ segundo discurso está relacionado à operacionalização do planejamento no ambiente de modelagem.

Assim, esta tensão foi constituída no envolvimento dos estudantes na discussão do tema da atividade, requerendo ações específicas: decidir o que perguntar aos alunos, em que momento organizá-los para resolver o problema, ou seja, como realizar a sequência e o ritmo das atividades planejadas na discussão do tema no ambiente de modelagem.

\section{A tensão da participação ${ }^{6}$ dos estudantes}

A professora Maria preocupou-se em propor atividades no ambiente de modelagem que propiciassem a participação ativa dos estudantes, tais como: coletar os dados para a resolução do problema e participar das decisões sobre as atividades propostas. Assim, nas primeiras aulas, Maria preocupou-se em envolver os estudantes na decisão da escolha dos itens na análise do consumo de água nas contas da escola e de suas casas como podemos observar no trecho abaixo:

Aí, surgiu a ideia de pedir que eles fizessem o acompanhamento da conta. Cada um vai trazer o consumo da casa e vai gerar uma nova discussão e o que vai apresentar da escola, vai gerar outra discussão. Neste momento, eu vi o seguinte: eu saber o processo que ele vai usar a Matemática, os conhecimentos matemáticos deles de uma maneira que ele não está sentindo que é uma coisa imposta. Ele é sujeito da ação. Eles sugeriram, eles participaram deste momento da escolha (ENTREVISTA, Professora Maria).

Nesta tensão, podemos observar que a professora reconheceu que o ambiente de modelagem requereu outras formas de interações entre professor e estudantes de maneira que viabilize a participação ativa deles. Essa 
preocupação de Maria esteve relacionada ao papel do professor no ambiente de modelagem e aconteceu no momento em que ela organizou os estudantes para realizar as atividades.

Nesta situação, a descontinuidade que constituiu a tensão nos discursos, denominada tensão da participação dos estudantes, pode ser representada pelas questões: Como intermediar o ambiente de modelagem sem centrar o processo no professor? Como requerer a participação dos estudantes? Essas questões evidenciam o isolamento entre a prática pedagógica de Maria que apresentava o discurso de centrar o processo de ensino e aprendizagem no professor e o discurso do professor como mediador, vinculado ao ambiente de modelagem.

Assim, esta tensão foi constituída na organização dos estudantes para realizar as atividades, requerendo ações específicas: decidir como propor atividades que envolvessem estudantes nas decisões delas para que eles participassem ativamente do ambiente de modelagem.

\section{A tensão da abordagem das respostas dos estudantes}

A professora Maria ficou preocupada em como discutir as diferentes escolhas apresentadas pelos estudantes referentes aos itens da conta de consumo de água como podemos observar no trecho a seguir:

Minha tensão está sendo como apresentar a conclusão para os itens dos alunos. E já surgiram várias questões. Quando eu coloquei no quadro todos os itens, eu fiquei preocupada em dar uma resposta a eles. $O$ que é que eu vou fazer para contemplar todos aqueles itens colocados pelos alunos sem fugir da modelagem? De repente, a gente pensa: será que colocando isso, nesse momento, eu não vou fugir da modelagem? Ou seja, é envolver de modo que eles vão criando as situações (ENTREVISTA, Professora Maria).

Essa tensão foi constituída em virtude da descontinuidade entre dois discursos: o primeiro, comentar e dar resposta para cada escolha dos estudantes e o segundo, solicitar que estudantes discutissem os itens escolhidos. Essa descontinuidade foi identificada nas seguintes perguntas: Posso responder as escolhas dos estudantes ou os deixo discutir? Como discutir e intervir diante das respostas apresentadas pelos estudantes? Essas questões estiveram presentes nos discursos dos professores e dizem respeito à produção de um discurso legítimo para operacionalizar a modelagem nas práticas pedagógicas, constituindo a tensão nos discursos denominada tensão da abordagem das respostas dos estudantes.

Assim, esta tensão foi constituída na apresentação das respostas dos estudantes para a atividade proposta, requerendo ações específicas: decidir como discutir e intervir diante das respostas apresentadas pelos estudantes.

\section{A tensão da abordagem do conteúdo matemático}

Os professores perceberam que os estudantes apresentaram dificuldades para mobilizar os conteúdos matemáticos para resolver os problemas no ambiente de modelagem. Diante disso, eles ficaram preocupados em como abordar o conteúdo matemático quando eles trazem problemas provenientes de situações do dia a dia para as práticas pedagógicas.

Como Vitória não sabia a priori o conteúdo matemático que seria utilizado na resolução do problema, ela ficou preocupada em como poderia abordar o conteúdo matemático no ambiente de modelagem. Vitória tentou abordar outros conteúdos durante a resolução do problema, como gráficos, mas os estudantes tiveram dificuldades em construílos a partir das informações coletadas sobre o problema como podemos observar no trecho abaixo:

Porque como eu já falei, eu fico sem saber quais são os conteúdos que vamos trabalhar. Eles têm muitas dificuldades com os conteúdos. No caso de gráfico mesmo, eles não sabem nem o que é o gráfico. Aí, eu queria trabalhar com gráficos, assim vários conteúdos matemáticos. Eu trabalhei até agora com as operações e porcentagem. Eu estou com dificuldades de trabalhar os outros conteúdos. Eu estou sem saber como trabalhar, porque eles não têm conhecimento dos outros conteúdos (Entrevista, Professora Vitória).

A professora Vitória abordava os conteúdos matemáticos nas aulas da seguinte maneira: apresentação de conceitos e procedimentos exemplos - exercícios. Com isso, no ambiente de modelagem, os estudantes resolveram as atividades relativas ao problema, utilizando o conteúdo 
abordado previamente nas aulas, no caso, porcentagem. Uma possível explicação é que os estudantes perceberam o problema apresentado por Vitória como mais uma atividade escolar e utilizaram o conteúdo estudado para resolvê-lo.

Os alunos apresentaram dificuldades em mobilizar conteúdos previamente estudados ou novos na resolução dos problemas e os professores tiveram que decidir como abordar o conteúdo matemático, constituindo a tensão nos discursos denominada tensão da abordagem do conteúdo matemático.

Assim, esta tensão foi constituída no acompanhamento dos estudantes na resolução dos problemas na atividade proposta, requerendo ações específicas: decidir como abordar o conteúdo matemático quando são utilizados problemas provenientes de situações do dia a dia nas aulas e em que momento fazer isso: antes, durante ou depois da atividade de modelagem.

\section{Discussão e conclusão}

As tensões foram manifestadas nos discursos dos professores nos momentos da operacionalização do ambiente de modelagem nas práticas pedagógicas, sendo representadas pelas questões que representam descontinuidades entre discursos no quadro a seguir:

Quadro 1 - Relação entre as tensões nos discursos e as questões

\begin{tabular}{|c|c|}
\hline QUESTÕES & TENSÕES NOS DISCURSOS \\
\hline Como sequenciar as atividades planejadas? & $\begin{array}{c}\text { Sequenciamento e ritmo da prática } \\
\text { pedagógica }\end{array}$ \\
\hline Como envolver os estudantes? & Participação dos estudantes \\
\hline $\begin{array}{c}\text { Como discutir as repostas dos estudantes? } \\
\text { Como intervir na abordagem das respostas } \\
\text { dos estudantes? }\end{array}$ & Abordagem das respostas dos estudantes \\
\hline $\begin{array}{c}\text { Como abordar o conteúdo matemático? } \\
\text { Qual momento abordar o conteúdo } \\
\text { matemático no ambiente de modelagem? }\end{array}$ & Abordagem do conteúdo matemático \\
\hline
\end{tabular}

Em termos bernsteinianos, essas questões estão relacionadas a reconhecer a produção de um discurso legítimo nos momentos da discussão do tema, da organização dos estudantes para realizar as atividades, das informações coletadas pelos estudantes e da resolução do problema como pode ser observada na tensão do sequenciamento e do ritmo na prática pedagógica, na tensão da participação dos estudantes, na tensão da abordagem das respostas dos estudantes e na tensão da abordagem do conteúdo matemático. Com isso, ações específicas foram requeridas para operacionalizar a modelagem nas aulas.

Os professores estruturam o ambiente de modelagem como uma atividade escolar, selecionando e sequenciando atividades para trabalhar os problemas oriundos de uma situação do dia a dia. Em termos bernsteinianos, podemos dizer que eles planejaram "o que falar" (classificação) e o "como falar" (enquadramento), controlando como o discurso sobre modelagem seria posicionado nas regras consolidadas nas práticas pedagógicas.

Com isso, eles organizaram o que falar e como falar na apresentação do tema e do problema, bem como na resolução do problema, tentando seguir com as atividades planejadas para o ambiente de modelagem. Entretanto, os estudantes envolveram-se além do previsto na discussão do tema e desafiaram o controle do "como falar", apresentando outros discursos fora da disciplina, requerendo outras ações dos professores para lidar com o envolvimento deles na discussão do tema.

Em decorrência das considerações sobre as tensões nos discursos, é possível afirmar que as tensões manifestadas estiveram relacionadas ao controle da comunicação e a produção de discursos legítimos quando os professores trouxeram o discurso sobre modelagem para as práticas pedagógicas, demandando ações específicas para implementação da modelagem nas aulas.

Em termos bernsteinianos, podemos analisar que tais ações dizem respeito à seleção, sequência, ritmo e critérios da comunicação na operacionalização da modelagem nas aulas. Ou seja, os momentos em que eles decidiram quais perguntas fazer aos estudantes e como fazê-las na apresentação do tema e das informações coletadas; estabeleceram uma sequência e ritmo com o 
propósito de viabilizar a realização das atividades planejadas para a resolução do problema; estabeleceram critérios para propiciar a participação dos estudantes; retomaram conteúdos matemáticos previamente abordados, bem como abordaram novos conteúdos.

A seguir, sistematizamos, no quadro abaixo, as tensões nos discursos e as ações requeridas no ambiente de modelagem.

Quadro 2 - Relação entre as tensões nos discursos e as ações

\begin{tabular}{|c|c|}
\hline TENSÕES NOS DISCURSOS & AÇÕES \\
\hline $\begin{array}{c}\text { Sequenciamento e ritmo da prática } \\
\text { pedagógica }\end{array}$ & Planejar o sequenciamento da aula \\
\hline Participação dos estudantes & Engajar os estudantes \\
\hline Abordagem das respostas dos estudantes & $\begin{array}{c}\text { Discutir e intervir diante das respostas dos } \\
\text { estudantes }\end{array}$ \\
\hline Abordagem do conteúdo matemático & $\begin{array}{c}\text { Decidir como abordar o conteúdo } \\
\text { matemático }\end{array}$ \\
\hline
\end{tabular}

Esse quadro apresenta 4 (quatro) tensões nos discursos relacionadas às ações da prática pedagógica em modelagem. Essas tensões são decorrentes das descontinuidades entre discursos que ocasionaram alterações na classificação e no enquadramento da prática pedagógica. Em relação à classificação, as alterações estiveram relacionadas ao que questionar aos estudantes na discussão do tema e das informações coletadas sobre o problema, bem como na resolução do problema, ou seja, "o que falar". Com isso, ações foram requeridas para planejar o sequenciamento da aula, discutir e intervir diante das respostas dos estudantes e engajá-los no ambiente de modelagem. Em relação ao enquadramento, as alterações estiveram relacionadas à maneira como ensinar o conteúdo matemático requerido na resolução do problema, ou seja, "como falar". Com isso, foi requerida a ação para decidir como abordar o conteúdo matemático e em qual momento fazer no ambiente de modelagem.

A literatura tem documento intervenções e estratégias utilizadas pelos professores na implementação da modelagem no contexto escolar. O estudo de Chapman (2007) apresenta duas estratégias que professores utilizaram para favorecer o engajamento de estudantes na realização de atividades voltadas para resolução de problemas: discutir o processo de resolução dos problemas nas aulas e trazer problemas para abordar os conteúdos matemáticos. No estudo de Lei $\beta$ (2005), professores realizaram as seguintes intervenções para orientar estudantes na resolução dos problemas: auxiliar estudantes na compreensão do problema para propiciar a construção do modelo; orientar estudantes na obtenção de informações sobre o problema e solicitar aos estudantes a reflexão sobre os seus processos de resolução do problema. Essas ações requeridas ao mover um novo discurso para as aulas apontam alterações nos princípios comunicativos da prática pedagógica para implementar a modelagem matemática. Com isso, essas ações se referem aos princípios comunicativos da modelagem matemática agendando o que falar $\mathrm{e}$ como falar.

$\mathrm{O}$ estudo das tensões nos discursos possibilita termos clareza sobre a inserção da modelagem nos contextos escolares no que se refere às ações dos professores para operacionalizar o ambiente de modelagem, bem como quais princípios comunicativos são estabelecidos na recontextualização do discurso sobre modelagem nas práticas pedagógicas.

Os resultados apontam que professores e estudantes foram os agentes que controlaram o posicionamento do discurso sobre modelagem na prática pedagógica. Em relação aos professores, eles estruturam o ambiente de modelagem como uma atividade escolar, planejando e organizando algumas atividades para trabalhar problemas provenientes de situações do dia a dia em termos das regras consolidadas na prática pedagógica. Em relação aos estudantes, eles trouxeram discursos externos à disciplina, o que permitiu um envolvimento inesperado deles na discussão sobre o tema da atividade de modelagem. Sendo assim, ações específicas foram requeridas para operacionalizar a modelagem nas aulas.

Esses resultados possibilitam trazer contribuições teóricas para a área de Educação Matemática e Educação no que se refere aos professores realizando mudanças de práticas no contexto escolar, fornecendo subsídios para 
compreender como eles movem discursos para as práticas pedagógicas e quais ações são requeridas para viabilizar a operacionalização deles nas aulas. Além disso, tais resultados podem gerar insights para os espaços de formação no que se refere às experiências que precisam ser proporcionadas aos professores para que os apoiem na implementação de propostas de mudanças das práticas pedagógicas.

\section{Notas}

1 Para evitar repetições textuais no decorrer do artigo, omitiremos a palavra matemática da expressão modelagem matemática.

2 Bernstein (2000) define prática pedagógica como as relações que ocorrem em um determinado contexto social para a reprodução e a produção de cultura. No âmbito do contexto escolar, é o locus onde ocorre as relações entre professor e estudantes para ensinar e aprender determinados conteúdos.

3 As situações de tensão são os momentos específicos na prática pedagógica, os quais as tensões nos discursos são manifestadas na implementação de um novo discurso. Essas situações de tensão são os loci das tensões nos discursos, as quais elas são constituídas.

4 Usaremos "enquadramento" para se referir a palavra framing como traduzido no artigo de Santos (2003).

5 Destina-se aos estudantes que apresentam idade avançada em relação ao ano de trabalho escolar. Nessa modalidade, os estudantes cursam dois anos de trabalho escolar durante o período de um ano.

6 A palavra participação será utilizada neste artigo para se referir ao envolvimento e engajamento dos estudantes no ambiente de modelagem.

\section{Referências}

ALMEIDA, L. M. W; DIAS, M. R. Um estudo sobre o uso da Modelagem Matemática como estratégia de ensino e aprendizagem. Boletim de Educação Matemática (Bolema), Rio Claro, n. 22, p. 19-35, 2004.

BARBOSA, J. C. Modelagem matemática e os futuros professores. In: REUNIÃO ANUAL DA ANPED, 25, 2002, Caxambu. Anais... Caxambu: ANPED, 2002. 1 CD-ROM.
BARBOSA, J. C. As relações dos professores com a Modelagem Matemática. In: ENCONTRO NACIONAL DE EDUCAÇÃO MATEMÁTICA, 8., 2004, Recife. Anais... Recife: Sociedade Brasileira de Educação Matemática, 2004. 1 CDROM.

BARBOSA, J. C. Integrando Modelagem Matemática nas práticas pedagógicas. Educação Matemática em Revista, Sociedade Brasileira de Educação Matemática - SBEM, Ano 14, nº 26, p. 17-25. Março de 2009.

BARBOSA, J. C., CALDEIRA, A. D.; ARAÚJO, J. de L. (Org.). Modelagem Matemática na Educação Matemática Brasileira: pesquisas e práticas educacionais. Recife: SBEM, 2007. 268 p.

BASSANEZI, R. C. Ensino-aprendizagem com modelagem matemática. São Paulo: Contexto, 2002. 389 p.

BERnSTEIN, B. Class, Codes and Control, volume IV: the structuring of pedagogic discourse. London: Routledge, 1990. $235 \mathrm{p}$.

BERNSTEIN, B. Pedagogy, symbolic control and identify: theory, research, critique. Lanham: Rowman \& Littlefield, 2000. 230 p.

BLOMHØJ, M.; KJELDSEN, T. H. Teaching mathematical modelling through project work. ZDM - The International Journal on Mathematics Education, Karlsruhe, v. 38, n. 2, p. 163-177, 2006.

BLUM, W. et al. Modelling and Applications in Mathematics Education: the 14th ICMI study. New York: Springer, 2007. 521 p.

CHAPMAN, O. Mathematical Modelling in high school mathematics: teachers' thinking and practice. In: BLUM, W.; GALBRAITH, P.; HENN, H.; NISS, M. (Eds.). Modelling and Applications in Mathematics Education: the $14^{\text {th }}$ ICMI study. New York: Springer, 2007. p. 325-332.

DENZIN, N. K.; LINCOLN, Y. S. Introduction: the discipline and practice of qualitative research. In: DENZIN, N. K.; LINCOLN, Y. S. (Ed.) Handbook of qualitative research. 3. ed. Thousand Oaks: Sage, 2005, p. 1-32. 
DOERR, H. M.; ENGLISH, L. D. Middle grade teachers' learning through students' engagement with modelling tasks. Journal of Mathematics Teacher Education, New York, n. 9, p. 5-32, 2006.

GAINSBURG, J. Real-world connections in secondary mathematics teaching. Journal of Mathematics Teacher Education, New York, v. 11, p. 199-219, 2008 doi: 10.1007/s10857-007-9070-8.

LEIß, D. Teacher intervention versus self-regulated learning? Teaching Mathematics and its Applications, v. 24, n.2-3, p. 75-89, 2005.

NISS, M.; BLUM, W.; GALBRAITH, P. L. Introduction. In: BLUM, W.; GALBRAITH, P.; HENN, H.; NISS, M. (Ed.). Modelling and Applications in Mathematics Education: the 14th ICMI study, New York: Springer, 2007. p. 3-32.

OLIVEIRA, A. M. P. Modelagem matemática e as tensões nos discursos dos professores. 2010. $199 \mathrm{f}$. TESE (Doutorado em Ensino, Filosofia e História das Ciências) - Instituto de Física/Departamento de
Ciências Exatas, Universidade Federal da Bahia e Universidade Estadual de Feira de Santana, Salvador, 2010.

OLIVEIRA, A. M. P; BARBOSA, J. C. Modelagem matemática e situações de tensão na prática pedagógica dos professores. Boletim de Educação Matemática (Bolema), Rio Claro, v. 24, n. 38, p. 265-296, 2011.

SANTOS, L. Bernstein e o campo educacional: relevância, influências e incompreensões. Cadernos de Pesquisa, São Paulo, n. 120, p. 15-49, nov., 2003.

SKOVSMOSE, O. Cenários para investigação. Boletim de Educação Matemática (Bolema), Rio Claro, n. 14, p. 66-91, 2000.

SKOVSMOSE, O. Educação crítica: incerteza, matemática, responsabilidade. Tradução de Maria Aparecida Viggiani Bicudo. São Paulo: Cortez, 2007. 304 p.

\section{Sobre os autores:}

Andreia Maria Pereira de Oliveira: Universidade Estadual de Feira de Santana (UEFS) - Feira de SantanaBA.

Jonei Cerqueira Barbosa: Universidade Federal da Bahia (UFBA) - Salvador-BA. 